\title{
INTIMATE: Integration of Ice core, Marine and Terrestrial Records of the Last Termination in the North Atlantic Region and Elsewhere
}

\author{
Zicheng YU ${ }^{1}$, Wim Z. Hoek ${ }^{2}$ and Rewi NeWnham ${ }^{3}$ \\ 'Department of Earth and Environmental Sciences, Lehigh University, Bethlehem, PA 18015, USA; ziy2@lehigh.edu \\ 2Department of Physical Geography, Utrecht University, 3508TC Utrecht, The Netherlands; w.hoek@geo.uu.nl \\ ${ }^{3}$ School of Geography, University of Plymouth, Plymouth PL4 8AA, UK; R.Newnham@plymouth.ac.uk
}

INTIMATE is a core project of the INQUA Palaeoclimate Commission. It was initiated during the XIVth INQUA Congress held in Berlin in 1995 by John Lowe (Royal Holloway, London) and Mike Walker (University of Wales, Lampeter). The project's primary goal has been to encourage collaboration between members of the ice-core, marine and terrestrial communities and to synthesize records during the last glacial-interglacial transition, with initial focus on the North Atlantic region. A milestone for the project was the development of an event stratigraphy for the last termination in the North Atlantic region based on the Greenland Ice Core isotope record and chronology (Björck et al. 1998).

INTIMATE has organized annual workshops since its initiation during the inter-congress periods as well as during the last two INQUA congresses in Durban, South Africa in 1999 (XVth) and in Reno, Nevada in 2003 (XVIth). Around the central goal of correlation of ice cores, marine and terrestrial records, the specific objectives for the project have changed over the years. As chronology is fundamental for the correlation and integration, the project has always strived to develop better ways for more precise and accurate dating of climatic events.

During the last four years INTIMATE has been successful in enlarging its North Atlantic scope in order to explore the issue of global synchroneity of the abrupt climate changes during the last glacial-interglacial transition. After the Reno INQUA Congress, the Australasian INTIMATE Project was established, and the original INTIMATE has become the North Atlantic INTIMATE Project. We are in the process of expanding the project to other regions to facilitate global synthesis.

The overall aims of the North Atlantic INTIMATE project are (a) to explore the potentials of different time-strati-

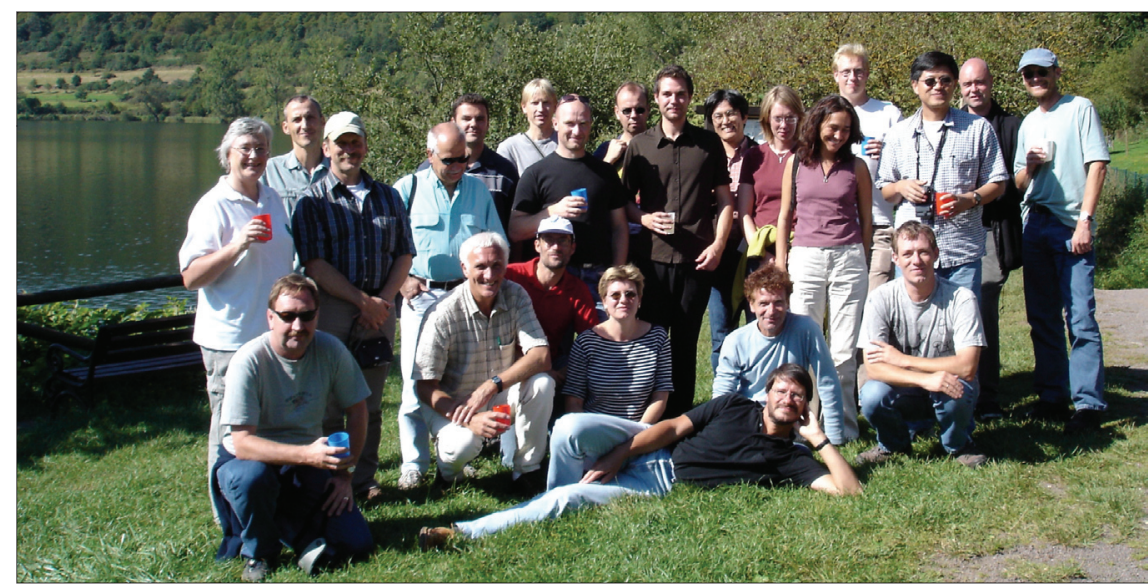

Fig. 1: Participants to the 7th International (North Atlantic) INTIMATE Workshop, held in Bonn, Germany on 15-18 September 2004. The photo was taken on September 17 at Meerfelder Maar in the Eifel Volcanic Field, Germany.

graphic marker horizons in ice-core, marine and terrestrial records; (b) to reduce the uncertainties in timing of events (e.g. spatial and temporal differences in marine reservoir ages); (c) to determine spatial patterns of events and gradients; and (d) to compare the data of spatial and temporal reconstructions with palaeoclimate model results.

The 7th International (the first North Atlantic) INTIMATE Workshop was held in Bonn and the Eifel Region, Germany on September 15-18, 2004, hosted by Thomas Litt (Friedrich-Wilhelms University, Bonn) and attended by 38 participants from 12 countries. The excursion to the Eifel Volcanic Field and the type locality of the Laacher SeeTephra was memorable (See Fig. 1). At the Workshop, the participants reviewed the progress during the 1999-2003 inter-congress period and refined the specific objectives of the North Atlantic INTIMATE group for the 2003-2007 inter-congress period. The workshop participants also decided to extend the time frame to cover the last glacial and early Holocene (30-8 ka). A representative from the Australasian INTIMATE project (Rewi Newnham) attended the workshop to facilitate synergy between two groups and between two hemispheres. The next North Atlantic (8th) INTIMATE
International Workshop will be held September 10-14, 2005 in Mýrdalur, Iceland, which will be hosted by Jón Eiríksson along with his colleagues. This Workshop will focus on the synthesis of paleoclimatic records in the North Atlantic Region during the last Glacial and early Holocene (30-8 ka). The topics of discussion include correlations of paleoclimate records using tephrochronology and the new INTCAL04 calibration data-set, identification and mapping of the key records in the region, and the new NGRIP timescale for the last Termination.

During the next (XVIIth) INQUA Congress in Cairns, Australia in 2007 the plan for the INTIMATE projects is to provide regional overviews and a joint global synthesis of reconstructions. We welcome inputs from paleo-scientists working on ice cores, marine and terrestrial records. If you have suggestions, please contact one of us. For additional information and the INTIMATE projects please visit the web site: http://www.geog. uu.nl/fg/INTIMATE/Welcome.htm.

\section{Reference}

Björck, S. and others., 1998: An event stratigraphy for the Last Termination in the North Atlantic region based on the Greenland Ice Core record: a proposal by the INTIMATE group. Journal of Quaternary Science, 13: 283-292. 